\title{
Die Anerkennung und Vollstreckung drittstaatlicher Entscheidungen in Zivil- und Handelssachen
}

\author{
Rechtsvergleichende Betrachtung und europäische Regelungsoptionen
}

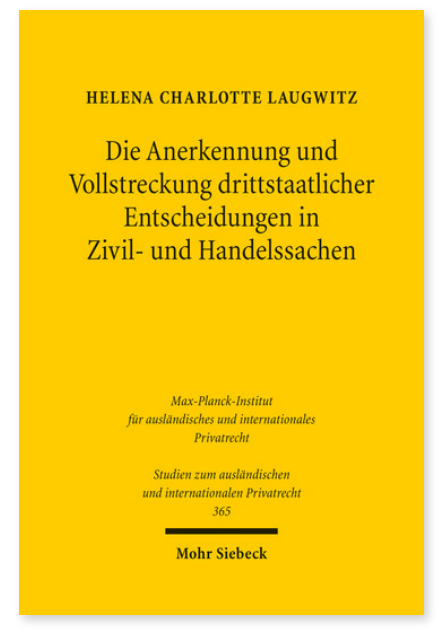

2016. XXV, 531 Seiten. StudIPR 365

ISBN 978-3-16-154410-1

DOI 10.1628/978-3-16-154410-1

eBook PDF 104,00€

ISBN 978-3-16-154409-5

fadengeheftete Broschur 104,00 €
Unter welchen Voraussetzungen entfaltet eine ausländische Entscheidung im Inland rechtliche Wirkungen? Seit der EuGVVO und dem Luganer Übereinkommen findet sich auf diese Frage hinsichtlich der Anerkennung und Vollstreckung von Entscheidungen aus dem europäischen Raum eine einheitliche Antwort. Bezüglich drittstaatlicher Entscheidungen ist der Rechtsanwender hingegen nach wie vor mit einem nur schwer zu handhabenden Normengeflecht aus autonomem Recht und Staatsverträgen konfrontiert.

Helena Laugwitz untersucht im Hinblick auf dieses komplexe Netz aus Rechtsquellen das deutsche, englische und französische Anerkennungsrecht und erarbeitet aufbauend auf den Ergebnissen ihrer rechtsvergleichenden Analyse europäische Regelungsoptionen.

Helena Charlotte Laugwitz Geboren 1984; Studium der Rechtswissenschaften und Begleitstudium des Europäischen Rechts in Würzburg und Genf; 2009 Erste Juristische Prüfung; Wissenschaftliche Mitarbeiterin am Lehrstuhl für Bürgerliches Recht, Europäisches Wirtschaftsrecht, Internationales Privat- und Prozessrecht sowie Rechtsvergleichung der Julius-MaximiliansUniversität Würzburg; 2012 Magister des Europäischen Rechts, LL.M. Eur. (Würzburg); Referendariat im OLG-Bezirk Frankfurt am Main/LG Darmstadt mit Stationen in Frankfurt am Main und New York; 2013 zweite juristische Staatsprüfung; seit 2014 Rechtsanwältin in Frankfurt am Main; 2015 Promotion.

Jetzt bestellen:

https://mohrsiebeck.com/buch/die-anerkennung-und-vollstreckung-drittstaatlicher-entscheidungen-in-zivil-undhandelssachen-9783161544101?no_cache $=1$

order@mohrsiebeck.com

Telefon: +49 (0)7071-923-17

Telefax: $+49(0) 7071-51104$ 